\title{
Benefits of an Abscission Agent in Mechanical Harvesting of Citrus ${ }^{1}$
}

Fritz Roka, Jackie Burns, Jim Syvertsen, and Robert Ebel ${ }^{2}$

An abscission agent is a chemical compound that when sprayed prior to harvest will induce physiological changes that reduce the picking force to remove mature citrus fruit from the tree. In the Florida citrus crop, an effective abscission agent could potentially boost the operational efficiency of citrus mechanical harvesting systems in four ways. First, and most important, an abscission agent will extend the harvest window of mechanical systems by allowing access to late-season Valencia orange acreage. Second, an abscission agent will allow a mechanical system to operate faster thus increasing its daily harvesting capacity. Third, an abscission agent may improve overall recovery percentages (i.e., the percentage of fruit that a mechanical harvesting system collects and delivers directly to a bulk trailer). Fourth, harvesting equipment operating in trees that have been sprayed with an abscission compound will require less force to remove fruit and thereby inflict less injury to citrus trees.

\section{The "Late-Season" Problem}

"Valencia" is a high quality orange variety that usually commands a price premium from juice processors. The Florida Valencia harvest typically takes place during the latter half of the harvest season-early March through June and sometimes into July, depending on crop size, fruit maturity, and processing capacity. In Florida, bloom occurs in the February-March period, and Valencia fruit require 14-16 months to mature. This means that throughout the entire harvest period, two crops are on the tree: this year's mature fruit and next year's growing young fruitlets. During most years, the young fruitlets grow to a one-inch ( $2-3$ centimeter) diameter by mid May.

The one-inch diameter size of a young Valencia fruitlet has become an important reference point for mechanical harvesting. Previous UF/IFAS research has suggested that a significant number of Valencia fruitlets greater than one-inch diameter are shaken loose along with the mature fruit during mechanical harvesting. Next year's yields may be reduced by at

1. This is EDIS document FE752, a publication of the Food and Resource Economics Department, Florida Cooperative Extension Service, Institute of Food and Agricultural Sciences, University of Florida, Gainesville, FL. Published September 2008. Please visit the EDIS website at http://edis.ifas.ufl.edu.

2. Fritz Roka, associate professor, Food and Resource Economics Department, Southwest Florida Research and Education Center, Immokalee, FL; Jackie Burns, professor, Horticultural Sciences Department, Citrus Research and Education Center, Lake Alfred, FL; Jim Syvertsen, professor, Horticultural Sciences Department, Citrus Research and Education Center, Lake Alfred, FL; and Robert Ebel, associate professor, Horticultural Sciences Department, Southwest Florida Research and Education Center, Immokalee, FL, Florida Cooperative Extension Service, Institute of Food and Agricultural Sciences, University of Florida, Gainesville, FL. Published September 2008. Please visit the EDIS website at http://edis.ifas.ufl.edu. 
least $25 \%$, and possibly as high as $50 \%$ (Roka et al. 2006; Whitney 1975; Whitney and Hedden 1973). It is important to note that this one-inch size reference point may be revised as new research on this subject continues.

Equipment operators can reduce the intensity of mechanical shaking to preserve next year's young fruitlets but only at a cost of poor removal of this year's mature crop. Any economic advantage with mechanical harvesting quickly dissipates if hand crews are required to glean a significant percentage of fruit after mechanical harvesting. Consequently, mechanical systems are often forced to shut down sometime during mid-to-late May. In fact, many growers err on the conservative side and suspend the Valencia mechanical harvesting by the end of April.

An effective abscission agent can alleviate the "late season" problem with the Valencia orange harvest by selectively loosening only the current year's mature fruit. If an abscission agent is used on a mature crop with young fruitlets of one-inch or more, the force applied by the harvesting machine can be scaled back; abscission agent application allows the mature fruit to be removed with less aggressive shaking. With less vigorous shaking, the next year's crop will be less adversely affected (Burns et al. 2006).

Application of an abscission agent should extend the window of mechanically harvesting Valencia oranges, gaining an additional four to six weeks of mature fruit harvesting per year with no effect on next year's yield. Seasonal capacity (i.e., number of boxes harvested per season) of a harvesting unit is increased. Fixed, or ownership, costs are spread over a greater number of harvested boxes which, in turn, drives down unit harvest costs. If a harvesting company can plan for the additional operating hours and expanded harvest capacity, lower unit harvest costs will result, not only to the late-season portion of Valencia acreage, but to early- and mid-season varieties as well, whether or not those acres are treated with an abscission compound.

\section{Harvest Speed}

With trees in prepared groves that have been skirted and pruned, continuous canopy shakers can travel between 0.50 and 1.25 miles per hour down a row and remove up to $95 \%$ of the mature crop. Trunk shakers require between five and ten seconds per tree to achieve a 95\% removal rate. An abscission agent loosens fruit by reducing a fruit's "pull-force," or the force necessary to remove it from the stem, thereby allowing mature fruit to come off the tree easier and more quickly. This means that canopy and trunk shakers can move faster and spend less time harvesting individual trees. Initial field trials in southwest Florida have shown that canopy shakers can increase harvest speeds to two miles per hour, and shake duration of trunk shakers can be reduced to two seconds while still removing 95\% of the fruit (Burns et al. 2005).

The economic value of faster harvest speed is contingent, however, upon a requisite increase in the number of daily trailers allocated to the harvest site. If faster harvest speeds increase acreage harvested by $33 \%$, then the number of trailers allocated by a processing plant to the harvest site has to increase by $33 \%$ as well. Simply filling the same number of trailers in less time will NOT change the cost structure of a harvesting system. As discussed in the "Late Season" section, the cost structure of a mechanical harvesting system is dependent upon the system's seasonal capacity. If faster harvest speeds translate into increased overall capacity, then unit costs will decrease.

\section{Recovery Percentage}

In theory, abscission agent application should enhance fruit recovery percentages of existing trunk and canopy shakers. Recovery percentage represents the portion of fruit hanging on the tree that is harvested and delivered to the bulk trailer through the mechanical harvesting system. Working in "prepared" groves, trunk and canopy shakers with catch frames recover between $88 \%$ and $92 \%$ of the available crop. Between $3 \%$ and $6 \%$ of additional fruit is removed but misses or falls through the catch frame. To a large extent, these missed pieces of fruit are "flung" outside the catch frame. Abscission 
agent application would reduce a fruit's pull-force and thus allow a more gentle harvesting action. If reducing machine aggressiveness decreases the likelihood of "fruit flinging," more fruit would hit the catch frame and overall fruit recovery should increase accordingly.

Whether abscission agent application can increase fruit recovery percentages remains a focus of ongoing research. Field trials consistently indicate that removal percentages are higher with abscission agent application. The ability to catch more fruit, however, may be a function of machine operation and improved catch-frame design rather than the use of an abscission compound. Increasing fruit recovery percentage is an important goal regardless of whether it is ultimately accomplished through abscission agent application or machine design. If recovery percentages from mechanical harvesters could be increased consistently to $95 \%$ or better, the expensive cost of hand gleaning (i.e., sending a hand crew into a mechanically harvested block of trees to recover fruit not delivered to the bulk trailer) could be eliminated.

\section{Reducing Tree Damage}

Previous UF/IFAS research has shown that neither trunk nor canopy shaking adversely affects short-term or long-term tree health (Li and Syvertsen 2005; Li et al. 2005). In addition, growers who have been mechanically harvesting for at least five years do not report production decreases or increases in tree mortality rates as a direct result of mechanical harvesting.

A number of growers, however, are not completely convinced. Mechanical harvesting systems inflict some visible cosmetic damage to trees. Leaf and stick litter on the ground are more pronounced at a mechanically harvested site than at a hand harvested site. Numerous limbs and trunks are scuffed and, in some cases, major scaffold limbs are broken. Research indicates that citrus trees are resilient to this damage, but many growers are disturbed by the aesthetic appearance of their grove after mechanical harvesting. As a result, some growers remain reluctant to commit fully to a mechanical harvesting program. Many growers refuse to use mechanical systems at all, or use only direct equipment to harvest in poorer or in declining blocks.

Reducing visible tree damage should assuage grower concerns about the mechanical harvesting impact on tree health. Abscission's role is to reduce the required pull-force to mechanically harvest fruit, and thereby lessen the need to operate equipment at high intensities. Less aggressive mechanical shaking should reduce cosmetic tree damage.

There is preliminary evidence suggesting that reducing visible tree damage with an abscission application reduces the amount of leaf and twig debris loaded into a bulk trailer from mechanical harvesting systems (Spann et al., preliminary results; Spann 2007). Decreasing the amount of valueless material transported to the processing plant has been an important objective for processing-plant managers. Reducing harvesting machine operational intensity may also carry positive effects on equipment maintenance. Operating the equipment at a lower intensity should lessen mechanical stress, and hence reduce equipment breakage and repair costs. As equipment usage increases and individual systems are pushed to their operational capacity, data will become available to address these hypotheses.

\section{Abscission Agent of Choice}

Among abscission agents, CMNP (5-chloro-3-methyl-4-nitro- $1 \mathrm{H}$-pyrazole) has emerged as the best candidate to be registered for use in citrus mechanical harvesting (Burns 2002). The compound is highly selective, has no long-term phytotoxic effect on leaves or young fruit ( $\mathrm{Li}$ et al. 2008), and does not defoliate the tree nor affect next year's production when used at recommended rates. Although CMNP may cosmetically scar the bottom or stem-end of the peel, the internal juice qualities of a fruit are unaffected. Registration of CMNP is progressing through EPA testing protocols, and special use permits should be available by the 2010-11 season. In the meantime, UF/IFAS is conducting research on up to ten acres per year (acreage limit by law) to develop successful management strategies for CMNP application and machine operation. The results of these field trials 
should allow harvesters to effectively apply CMNP and exploit the benefits from abscission agent application by (1) extending the harvest window, (2) increasing harvest speeds, (3) enhancing fruit recovery, and (4) minimizing cosmetic damage to trees.

For more information about citrus mechanical harvesting, please visit the UF/IFAS Citrus Mechanical Harvesting Program Web site at http://citrusMH.ifas.ufl.edu.

\section{References}

Burns, J.K. 2002. Using molecular biology tools to identify abscission materials for citrus. HortScience 37: 459-464.

Burns, J.K., R. Buker, and F. Roka. 2005. Mechanical harvesting capacity in sweet orange is increased with an abscission agent. HortTechnology 15: 758-765.

Burns, J.K., F. Roka, K. Li, J. Pozo, and R. Buker. 2006. Late-season Valencia orange mechanical harvesting with an abscission agent and low-frequency harvesting. HortScience 41(3): 660-663.

Li, K-T., J.K. Burns, and J. Syvertsen. 2008. Recovery from phytotoxicity after foliar application of fruit loosening abscission compounds to citrus. Journal of the American Society for Horticultural Science 133: (in press).

Li, K. and J. Syvertsen. 2005. Mechanical harvesting has little effect on water potential and leaf gas exchange in citrus trees. Journal of the American Society for Horticultural Science 130(5): 661-666.

Li, K-T. and J.P. Syvertsen, 2005. Mechanical harvesting has little effect on water status and leaf gas exchange in citrus trees. Journal of the American Society for Horticultural Science 130: 661-666.

Li, K-T., J.P. Syvertsen, and J.K. Burns. 2005. Mechanical harvesting of Florida citrus trees has little effect on leaf water relations or return bloom. Proceedings of the Florida State Horticulture Society 118: 22-24.
Roka, F., J.K. Burns, and R. Buker. 2005. Mechanical harvesting without abscission agents yield impact on late Valencia oranges. Proceedings of the Florida State Horticulture Society 118: 25-27.

Spann, T.M. 2007. Mechanical harvesting: a trashy business? Florida Grower 100(9): 18.

Whitney, J.D. 1975. Orange yield and removal studies with air and trunk shakers using two abscission chemicals. Proceedings of the Florida State Horticulture Society 88: 120-124.

Whitney, J.D. and S.L. Hedden. 1973. Harvesting Valencia oranges with a vertical foliage shaker. Proceedings of the Florida State Horticulture Society 86: 41-48. 